\title{
LAS MORALES DE DIEGO GRACIÁN DE ALDERETE EN LA ESTANTERÍA: PLUTARCO EN LAS COMEDIAS DE LOPE DE VEGA
}

El interés de la crítica por encontrar trazas de los autores clásicos en la obra de Lope de Vega se ha revitalizado durante los últimos años ${ }^{1}$, aunque, en realidad, no se estaría haciendo otra cosa salvo caminar sobre las huellas dejadas por otros. Desde que, allá por los años treinta, A. K. Jameson escribiera su sugerente trilogía de artículos ${ }^{2}$, los especialistas se han preguntado con insistencia si Lope fue o no un hombre verdaderamente culto, si la erudición esparcida por sus libros nacía de su memoria o de un centón de su biblioteca o, peor aún, de algún viejo cartapacio de retales, como le acusó uno de sus enemigos ${ }^{3}$.

De todos modos, si consideramos lo que la tradición crítica entiende por "cultura del Barroco", ahora a salvo de aquellas orejeras de la lucha entre propaganda y subversión, los bienes de consumo en la Edad Moderna cumplían una función muy parecida a la que tienen hoy en las sociedades capitalistas del siglo Xxi. En particular, el libro, como transmisor de ideas, estableció un vínculo poroso entre el lector y su contenido, puesto que, por un lado, ya no se necesitaba tanto de la memoria

1 En 2005 se celebró en Barcelona el V Congreso Internacional Lope de Vega, donde se trató el tema de forma exhaustiva. Las ponencias y comunicaciones leídas entonces se recogieron en los números 11 y 12 del Anuario Lope de Vega, cuya consulta recomendamos.

2 A. K. Jameson, "Lope de Vega's knowledge of classical literature", $\mathrm{BHi}$, 38 (1936), 444-501; “The sources of Lope de Vega's erudition”, HR, 5 (1937), 124-139; "Lope de Vega's La Dragontea: Historical and literary sources", HR, 6 (1938), 104-119.

3 "Virgilio lo enseñó en uno de los más comunes versos de su obra, que es imposible deje de estar en su cartapacio viejo donde tiene el retal de los latines que encaja en sus prosas a troche y moche" (J. DE EnTRAmbasaguas, Estudios sobre Lope de Vega, CSIC, Madrid, 1946-1958, t. 2, p. 482). 
para aprender, al tener el conocimiento siempre a la mano, y, por otro, la difusión de la imprenta había abierto el mercado a casi cualquier bolsillo, produciéndose una "vulgarización" de la sabiduría. Lope y el resto de hombres de la época, fascinados por lo rápido que cambiaba aquella sociedad abierta a un Nuevo Mundo, eran en definitiva el producto de su tiempo, esto es, el resultado del impacto que había tenido el acceso a la cultura escrita. Como explica la cultura material, heredera interdisciplinar de aquellos estudios sobre la vida cotidiana de Herrero García o Deleito y Piñuela, el escrutinio del objeto como árbitro cultural, y no sólo como mero producto de consumo, hace posible la reconstrucción de la cultura del Barroco por medio de la desgravitación de su centro:

Si por lo general se ha concebido este período como el triunfo del individualismo, situando al sujeto en el centro del análisis, se trata ahora de invertir los términos y preguntarse cuál ha sido el papel del objeto, qué relevancia ha tenido en la formación de esta cultura ${ }^{4}$.

Por consiguiente, la actitud de Lope, incluso aceptando su lado censurable, no sería nada más que un modelo de conducta dentro de la cultura propia de su siglo, fruto de aquella relación dinámica entre sujetos y objetos que explicó Daniel Miller ${ }^{5}$, y que al final proporcionaba una rentabilidad estética al poeta, que demostraba así una elocutio superior a sus rivales.

Para un artista del Renacimiento, el debate entre imitación u originalidad olía a viejo, pero no desplegaba los mismos parámetros que presenta hoy en día, donde seguimos fuertemente influenciados por la cosmovisión romántica. La imitatio como medio legítimo para superar, si alcanzaba el ingenio, a los grandes autores clásicos era un precepto obligado en tiempos de Lope ${ }^{6}$. El

4 E. García Santo-Tomás, "Barroco material/material barroco", en Materia crítica: formas de ocio y de consumo en la cultura áurea, IberoamericanaVervuert, Madrid-Frankfurt/M., 2009, pp. 1-32. Este punto de vista entra en contacto con lo que crítica inglesa denominó con más o menos acierto Nuevo materialismo. Consúltese la abundante bibliografía en E. García SANTO-Tomás, pp. 29-32.

5 D. Miller, Material culture and mass consumption, Basil Blackwell, London, 1987.

${ }^{6}$ En el De disciplinis de J. L. Vives (1531) se lee: "En lo puramente humano, puede ser tal el aprovechamiento que un hombre alcance a otro hombre y aunque le tome ventaja vaya delante de él. Por lo cual, lo que a los comien- 
principio de auctoritas no sólo se invocaba para refrendar o resolver una confrontación de ideas, sino también para constituir un modelo fijo, estable y canónico para escribir, pintar o cualquier otra actividad artística. Como ya explicara Lázaro Carreter a cuenta de la lírica del siglo Xvi, los escritores se podían catalogar según el modo o grado de imitación del modelo clásico que tuvieran enfrente. Por un lado estaban los "gusanos de seda", una imagen casi utópica para los que creaban con la seda producida por sus propias vísceras. En otras palabras, los poetas que sólo se servían de su creatividad7. En el otro extremo estaban las "hormigas", que almacenaban en sus nidos los granos robados a otro y que, por tanto, definía a los escritores que se limitaban a pergeñar una imitación servil del modelo. Entre ambas posturas podríamos situar a las "abejas", que libaban en numerosas flores antes de elaborar su propia miel. Era aquel modo de imitar el que, a decir verdad, más se ajustaba al verdadero ideal renacentista. Aquella bella imagen, que se remontaba a Aristófanes, sería recuperada por el mundo latino de la mano de Horacio, Lucrecio y, sobre todo, Séneca ${ }^{8}$, para siglos más tarde ser retomada por Petrarca, por medio del cual se difundió por toda la Europa cristiana:

Michi quidem, fateor, de hac re non amplius quam unicum consilium est; quod si fortassis inefficax experimento deprehenderis, Senecam culpabis; at si efficax, sibi non michi gratiam referes; denique, in omnem eventum, illum habeas velim consilii huius auctorem. Cuius summa est: apes in inventionibus imitandas, que flores, non quales acceperint, referunt, sed ceras ac mella mirifica quadam permixtione conficiunt ${ }^{9}$. ("Sobre este asunto...", Petr., Fam. I, 8, 2: la traducción es nuestra.)

zos es imitación, poco a poco debe progresar hasta un punto en que ya sea competencia y decidido propósito no sólo de igualar, sino de superar, si es ello posible. La simple imitación jamás llega a parearse con el dechado que se propuso; pero en la competencia puedes dejar a la espalda a aquel con quien entablaste el pugilato" (Obras completas, ed. L. Riber, Aguilar, Madrid, 1947-1948, t. 2, p. 469).

${ }^{7} \mathrm{Ni}$ siquiera en este caso podríamos hablar de originalidad, no al menos en su sentido moderno, pues imitar sin un modelo en la cabeza resultaba incomprensible para el hombre del Renacimiento.

${ }^{8}$ F. LÁzaro Carreter, "Imitación y originalidad en la poética renacentista”, en Historia de la literatura española, t. 2: Siglos de Oro: Renacimiento, ed. F. López Estrada, Crítica, Barcelona, 1980, p. 91.

9 "Sobre este asunto, lo confieso, sólo te doy un único consejo, que si por casualidad llegases a darte cuenta de que es ineficaz para tus experimentos, le echarás la culpa a Séneca, pero si es eficaz, le darás las gracias a 
Si hablamos de Lope es harto difícil, casi temerario, encuadrarle en ninguna categoría, pues, sin asomo de duda, era un poco de todas: posiblemente, un gusano de seda disfrazado de abeja que en caso de necesidad no tenía escrúpulos para hacer de hormiga. $\mathrm{O}$ dicho de otra manera, un escritor que confiaba su suerte al ingenio más que a sus lecturas. Tampoco podemos culparle. No era fácil ser poeta en el Siglo de Oro. La poesía, en particular, se consideraba como compendio de todas las ciencias, por lo que debía aglutinar en torno suyo la geografía, la medicina, la filosofía, las matemáticas y cualquier otro conocimiento intelectual que diera lustre, afeite y cuerpo a los versos. Recuérdense las palabras de don Quijote:

La poesía, señor hidalgo, a mi parecer es como una doncella tierna y de poca edad y en todo estremo hermosa, a quien tienen cuidado de enriquecer, pulir y adornar otras muchas doncellas, que son todas las otras ciencias, y ella se ha de servir de todas, y todas se han de autorizar con ella ${ }^{10}$.

Por lo tanto, para alcanzar el rango de poeta culto no bastaba con practicar los géneros y metros altos, como la épica o la octava real, por ejemplo, sino que se exigía una erudición superior en las más diversas disciplinas. Para lograr semejante sabiduría se necesitaban un talento extraordinario -ingenium-, muchos años de dedicación al estudio - ars ${ }^{11}$ - y una retentiva enciclopédica-memoria-, es decir, había que reunir las cualidades pedagógicas consideradas como fundamentales para la formación del vir doctus. Parecía una meta imposible para un poeta como Lope, que había nacido en una familia humilde, sin recursos, y que apenas había completado sus estudios universitarios. Sin embargo, su ambición, que siempre le llevó a anhelar el aplauso unánime como el mejor de los poetas españoles, le arrastró a intentar demostrar una y otra vez que era un poeta leído, culto y versado en cualquier materia. Así que desde sus primeras obras

él, no a mí. En fin, me gustaría que en cualquier caso le considerases autor de este consejo: las abejas han de ser imitadas en sus quehaceres porque no devuelven las flores como las han cogido, sino que mediante una maravillosa transformación producen cera y miel".

${ }^{10}$ M. De Cervantes, Don Quijote de la Mancha, coord. F. Rico, Crítica, Barcelona, 1998, t. 1, p. 757.

11 Por lo general, los humanistas entendían el ars como la conjugación del estudio -studium - con la práctica o ejercicio -exercitatio-, siendo uno de los más recomendados la imitatio, de la que ya hemos hablado anteriormente. 
se dispuso a acicalar su prosa y su verso con un conocimiento del mundo que a veces desbordaba lo razonable. Una exhibición intelectual tan increíble que pronto sería satirizada por sus detractores, reacios a aceptar que aquél que componía versos como buñuelos, que diría Góngora, tuviera además tiempo, voluntad y juicio para domeñar todas las ciencias conocidas ${ }^{12}$.

Sin entrar en el viejo debate sobre la cultura de Lope, si era mucha o poca, propia o de segunda mano ${ }^{13}$, parece evidente que estuvo muy cerca de conseguir su objetivo. Desde muy joven se granjeó el apoyo fervoroso de su querido vulgo y de una parte importante de los literatos, artistas y profesionales liberales de la época, fascinados por el genio poético del Fénix. Aquella masa de incondicionales menguaría un tanto con el paso de los años, incluso habría algunas deserciones importantes; sin embargo, le demostraría su devoción incluso después de muerto ${ }^{14}$.

Sólo le faltó rendir a la Corte, es decir, al Rey, los grandes señores y las autoridades de gobierno, a los que también llegaría a seducir, aunque es cierto que no por completo, pues nunca se acabaron de entregar a un hombre tan famoso por sus versos como por sus escándalos públicos y privados. A la postre, susceptible a su vida libertina, la Corte terminaría por darle la espalda con el ascenso al trono de Felipe IV, su todopoderoso valido y la rígida Junta de Reformación ${ }^{15}$. Sus repetidos intentos por con-

12 “Los versos de Lope de Vega, en sacándolos del teatro son como los buñuelos, que en enfriándose no vuelven a tomar la sazón que antes, aunque los vuelvan a la sartén” (E. Orozco DíAz, Lope y Góngora frente a frente, Gredos, Madrid, 1973, p. 400).

13 V. Dixon, "Lope's knowledge", en A companion to Lope de Vega, eds. A. Samson \& J. Thacker, Tamesis Books, Rochester, 2008, pp. 16-22.

14 Recuérdense las emotivas palabras de J. Pérez de Montalbán acerca de su multitudinario sepelio: "Empezose el entierro según estaba prevenido y fue tan dilatado, que estaba la cruz de la parroquia en San Sebastián y no había salido el cuerpo de su casa... Las calles estaban tan pobladas de gente, que casi se embarazaba el paso del entierro, sin haber balcón ocioso, ventana desocupada ni coche vacío. Y así, viendo una mujer tanta grandeza, dijo con mucho donaire: «Sin duda, este entierro es de Lope, pues es tan bueno»" (Fama póstuma de Lope de Vega, Rafael Peregrina, México, 1966, pp. 27-28).

15 Esto no quiere decir que a Lope no le encargaran comedias para palacio o autos sacramentales para el Corpus Christi, especialmente en tiempos de Felipe III, donde fue incluso el "poeta más reconocido de la corte" (J. OlezA, "El nacimiento de la comedia: estado de la cuestión”, en La comedia: seminario hispano-francés, ed. J. Canavaggio, Casa de Velázquez, Madrid, 1995, p. 198). Su inmenso éxito popular le abrió las puertas de cabildos, palacios y ayuntamientos, de donde le llegaron numerosos proyectos de espectáculo para fiestas cortesanas y celebraciones públicas. 
seguir el puesto de Cronista real cayeron siempre en saco roto ${ }^{16}$. Para mayor desgracia, Luis de Góngora y su "nueva poesía" ocasionaban un verdadero terremoto en las aulas, tertulias y academias de Madrid, que poco a poco se iban rindiendo ante aquel novedoso lenguaje poético que, como si de una moda extranjera se tratara, se abría paso de manera arrolladora. Los laureles poéticos de la nación, que llevaban muchos años reposando en la frente del madrileño, estaban ahora en seria disputa. El triunfo final del gongorismo fue patente aunque Lope continuara luchando hasta el último día ${ }^{17}$, pero estamos convencidos de que el devenir de aquella guerra literaria hubiera sido otro sin el favor, regalo y beneplácito de la Corte hacia Góngora ${ }^{18}$, que provocó que muchos ingenios, ya fuera por gusto o conveniencia, abandonaran el círculo del Fénix y se pasaran al lado de la "nueva poesía"19.

Sin embargo, a pesar de tantos sinsabores, infortunios y fracasos, Lope no dejó nunca aquel rasgo tan controvertido, pero a la vez tan personal, de su usus scribendi: embellecer el estilo con citas, textos y argumentos eruditos. Un alarde de conocimientos que se ha achacado con razón a la ayuda, manejo y abuso de las polianteas de la época, que a modo de primitivas enciclopedias encerraban el saber de la Antigüedad clásica. Compendios, florilegios y misceláneas que no eran otra cosa que la respuesta comercial a la recomendación humanista (Erasmo, Juan Luis Vives, Miguel de Salinas, Lorenzo Palmireno, Justo Lipsio, etc. $)^{20}$ de elaborar un cartapacio escolar o codex excerptorius donde anotar todo lo interesante que se iba leyendo y que pudiera tener cierta utilidad más adelante. Algunos de aque-

16 Para tener una visión panorámica de sus sucesivas tentativas para hacerse con el cargo, consúltese el artículo de H. Bershas, "Lope de Vega and the post of royal chronicler”, HR, 31 (1963), 109-117.

17 J. GonzÁlez-Barrera, "Las bizarrías de Belisa o la última bala contra los «pájaros nuevos»”, Monteagudo, 15 (2010), 105-118.

18 Como prueba del favor real hacia la "nueva poesía", a finales de 1617 el poeta cordobés era premiado con una capellanía de honor por orden de Felipe III.

19 Probablemente, el caso más llamativo sea el del sevillano Juan de Jáuregui (1583-1641), que en pocos años pasó de ser el autor del Antídoto contra la pestilente poesía de las Soledades (1615-1616?) a escribir el Orfeo (Madrid, 1624), donde se compone sin disimulo al modo de la "nueva poesía", suscitando las iras de Lope y sus partidarios.

${ }^{20}$ Los argumentos de cada uno de ellos se pueden leer en una nota admirable de S. López Poza, "Polianteas y otros repertorios de utilidad para la edición de textos en el Siglo de Oro”, La Perinola, 4 (2000), p. 192, n. 3. 
llos mamotretos, como la Officina de Ravisius Textor (1520) o la Polyanthea de Nanus Mirabellius (1503), fueron los primeros best sellers a nivel continental que alumbró la imprenta ${ }^{21}$ y se pueden hallar en las bibliotecas de grandes humanistas como Juan de Mal Lara, Rodrigo Caro y Cristóbal de Salazar, por lo que es de suponer que aquellos libros no sólo eran aprovechados por la masa estudiantil. Por consiguiente, no se puede ignorar el hecho de que el uso de aquellos centones fue una práctica común en el Siglo de Oro y no una artimaña del "ingenio lego" de Lope ${ }^{22}$.

\section{La recepción de Plutarco}

Si nos centramos en el otro núcleo de este trabajo, es decir, Plutarco, habría que empezar diciendo que por mucho que leyéramos sus obras, resulta complicado retener frases o párrafos enteros dentro de una producción tan desmesurada, posiblemente como pocos escritores de la Antigüedad, de la que, sin embargo, apenas nos ha llegado un tercio ${ }^{23}$. Es cierto que el hombre del Siglo de Oro ejercitaba su memoria mucho más que nosotros. Ya desde la escuela el niño asimilaba los conocimientos a base de memorizar cuadernillos, vocabularios y breviarios $^{24}$. Ahora bien, aclarado esto, que Lope leyó a Plutarco es un hecho contrastado, como demostraremos en las páginas

${ }^{21}$ Según los cálculos de V. Infantes, sólo la magna obra del humanista de Nevers superó las treinta ediciones y cincuenta mil libros vendidos en el siglo xvi ("De Officinas y Polyantheas: los diccionarios secretos del Siglo de Oro", en Homenaje a Eugenio Asensio, Gredos, Madrid, 1988, p. 247).

22 "Estas polyantheas circularon, se consultaban, se compraban y se ocultaba (habitualmente) la cita de su conocimiento... Una cultura que hace gala de la propia cultura como emblema (valga el CLXXXII de Alciato: "Antiquissima quaeque commentitia»)" (ibid., pp. 245-246).

${ }^{23}$ Según el Catálogo de Lamprias (siglos III-IV de nuestra era) que reseña 227 títulos, sólo conservamos en nuestras bibliotecas ochenta y tres completos y quince más en diversos fragmentos. Si a estos números añadimos los dieciocho que no se recogen en el Catálogo y otros quince no adscritos que han sobrevivido al paso del tiempo de forma parcial o indirecta, tendríamos un total de 260 obras, de las que en torno a diez se consideran de atribución dudosa.

${ }^{24}$ El método pedagógico de los jesuitas, tan celebrados por sus excelentes colegios, era el mejor paradigma. En el caso del latín, por ejemplo, se recomendaba anotar cualquier palabra nueva para poder memorizar su significado más adelante, por lo cual los cartapacios de los estudiantes se acabaron convirtiendo en verdaderos diccionarios. 
siguientes, pero que tuviera cabeza suficiente para recitarlo de corrido es más difícil de creer.

Plutarco no fue un descubrimiento humanista, pues ya era conocido en la Edad Media gracias sobre todo al renacimiento bizantino ${ }^{25}$. No obstante, su nombre aparecía ligado con frecuencia a leyendas extrañas, como aquélla que le honraba como preceptor del emperador Trajano u otra que le convertía en testigo de los apóstoles ${ }^{26}$. Precisamente, será en la Península ibérica donde nos toparemos con uno de los primeros hitos en la transmisión de su obra: a finales del siglo XIV se hace la primera traducción de Plutarco en lengua romance, concretamente al aragonés y de las Vidas paralelas, encargada por el gran maestre de la Orden del Hospital, Juan Fernández de Heredia (ca. 1310$1396)^{27}$. Por desgracia, para leer las Vidas en castellano hubo que esperar todo un siglo ${ }^{28}$.

Los años pasaron y con la llegada del Renacimiento el interés por Plutarco fue creciendo según se iban rescatando nuevos títulos de las bibliotecas del Oriente. A pesar de que arrastraba la etiqueta medieval de ser uno de los grandes historiadores de la Antigüedad, en su aspecto de moralista cosechó su triunfo entre los doctos, que se lanzaron con entusiasmo a la edición, translatio y comentario de sus obras. En realidad, puede decirse que el polígrafo griego atrajo tanto a ortodoxos como heterodoxos ${ }^{29}$. Si atendemos a su paso por la imprenta, en la monarquía hispánica el panorama editorial estuvo un tanto desequilibrado respecto al resto de la Europa cristiana. El bajo

${ }^{25}$ Para ahondar en la impronta que dejó Plutarco en la España del Siglo de Oro contamos hoy en día con una amplia bibliografía, de la que podemos destacar los estudios de A. Pérez Jiménez, "Plutarco y el humanismo español del Renacimiento", en Estudios sobre Plutarco. Obra y tradición, eds. A. Pérez Jiménez y G. del Cerro, Universidad, Málaga, 1990, pp. 229-247; J. Bergua Cavero, Estudios sobre la tradición de Plutarco en España (siglos XIIIXVII), Universidad, Zaragoza, 1995, y A. Morales Ortiz, Plutarco en España: traducciones de "Moralia" en el siglo XVI, Universidad, Murcia, 2000; por citar algunos de los más relevantes.

${ }^{26}$ Aquella visión distorsionada de la vida de Plutarco tuvo su origen en textos apócrifos como el Institutio Traiani, que durante siglos se atribuyó al propio escritor de Queronea.

27 Para conocer la biografía de este mecenas de las artes, véase el libro de J. M. Cacho Blecua, El gran maestre Juan Fernández de Heredia, Caja de Ahorros de la Inmaculada de Aragón, Zaragoza, 1997.

${ }^{28}$ La primera traducción castellana llegó un siglo después, concretamente en 1491, a cargo de Alfonso Fernández de Palencia.

29 A. Pérez Jiménez, art. cit., p. 240. 
número de publicaciones demostró una penetración comercial inhóspita, aunque no parece que sucediera lo mismo en las aulas universitarias, como explicaremos más adelante. El éxito editorial de Plutarco se constriñó a un puñado de traducciones latinas o castellanas ${ }^{30}$, quedando a un lado la editio en lengua griega, como, por otra parte, era norma y castigo para los helenistas de la época, que se veían incapaces de encontrar patronazgo para semejantes trabajos filológicos:

Tampoco se hicieron ediciones griegas, algo comprensible en el pobre panorama de la edición de textos griegos en España, explicable, en este caso como en otros, por las dificultades económicas y tipográficas de las que los propios humanistas suelen lamentarse. Sí debieron circular abundantemente las vulgatas latinas, tanto de la Moralia como de las Vidas, y es con toda probabilidad la edición princeps de Aldo Manuzio, al menos para la Moralia, el texto griego que tuvieron con mayor facilidad a su alcance los estudiosos ${ }^{31}$.

Por otra parte, el escritor de Queronea fue estudiado con contento en las universidades españolas, no sólo por el fruto, utilidad y provecho de su doctrina, sino por la sintaxis no excesivamente dificultosa de sus libros, que lo convertía en un autor recomendado para un primer aprendizaje del griego clásico. En general, el embeleso de los doctos por Plutarco se explica porque en él hallaban unas características que casaban a la perfección con el ideal religioso de la docta pietas, por el que tanto abogó Petrarca -y más tarde Erasmo-, para escapar de la literata ignorantia o devota rusticitas, ambas igualmente indeseables:

La figura de Plutarco, al igual que la de Sócrates, adquiere una fisionomía nueva. Es el vir bonus, el escritor preocupado por la formación del individuo. Es, en definitiva, un gentil que conoció esa verdad universal que buscaban con tanto anhelo los humanistas con el deseo de realizar la síntesis de las religiones ${ }^{32}$.

Desde la Antigüedad se le consideró como uno de los autores paganos más próximos a la fe de Cristo e incluso se difundió el mito de que había asistido a las predicaciones de los apóstoles. Esta visión folclórica de Plutarco es rescatada por los huma-

${ }^{30}$ J. Bergua Cavero, op. cit., pp. 1-34.

31 A. Morales Ortiz, op. cit., pp. 85-86.

32 A. Blecua, "La literatura apotegmática en España”, en Signos viejos y nuevos. Estudios de historia literaria, Crítica, Barcelona, 2006, p. 278. 
nistas, que siempre lo consideraron como una lectura idónea para el enriquecimiento de un espíritu piadoso. Por este motivo, su faceta como historiador quedó en un segundo plano, y los Moralia se convirtieron entonces en el principal foco de estudio. Erasmo llegó a afirmar que no había nada más provechoso, al margen de las Sagradas Escrituras:

En estos trabajos [traducir a Plutarco] me ejercitaba deleitosamente, porque, aparte de la pericia del idioma, eran convenientes para la formación de las costumbres. Yo, aparte de las Sagradas Escrituras, no leí jamás cosa más edificante ${ }^{33}$.

Sin olvidar, en otro orden de cosas, que la huella del polígrafo griego se puede seguir de manera nítida más allá de los claustros universitarios o el bufete de los humanistas. Es conocido por todos que se ha documentado abundante material plutarqueo en la obra original de muchos ingenios del Siglo de Oro, como Cristóbal de Villalón, Melchor de Santa Cruz, Ruiz de Alarcón, y así un largo etcétera. Lope de Vega no fue indiferente a esta tendencia y, siguiendo su particular usus scriben$d i$, trufó sus comedias de abundantes noticias suyas, de las que a continuación mostraremos un número significativo, pero sin la voluntad de agotar el tema, dada la magnitud de la producción dramática del poeta madrileño. Unas referencias cuantiosas entre biografías y obras de costumbres que dejarían al desnudo la evidencia de que el Fénix se valió de una traducción castellana para lucir estas últimas.

\section{Plutarco en el teatro de Lope de Vega: Moralia}

Para empezar, habría que advertir que, en el Seiscientos, el rastreo de una fuente para Plutarco resulta harto complicado, debido al considerable abanico de posibilidades. Incluso tomándonos la licencia de marginar las ediciones griegas, con la princeps de Aldo Manuzio como estandarte (1509), lo cierto es que nuestra atención derivaría entonces hacia un doble frente: por un lado, las traducciones latinas, tanto dentro como fuera de nuestras fronteras, y las versiones españolas, que son tan pocas que se podrían enumerar en un momento: las Morales de

33 Erasmo, Obras escogidas, ed. L. Riber, Aguilar, Madrid, 1956, p. 108. 
Diego Gracián de Alderete $(1548)^{34}$, los Apothegmas de Erasmo -basados en Plutarco- por Francisco Támara (1549) ${ }^{35}$, el Diálogo de cómo se ha de refrenar la ira y la Carta de casamiento de Diego de Astudillo, publicadas juntas (1551), y la anónima Contra la codicia $(1538)^{36}$. Es posible que Lope tuviera en su casa todas o ninguna, pero a la luz de los datos que nos ofrecen sus comedias podríamos estar en disposición de confirmar que cuanto menos poseyó una: las Morales de Diego Gracián, a la que recurre cada vez que tiene ocasión.

Así, valga como primer ejemplo, en la dedicatoria dirigida al doctor Cristóbal Núñez ${ }^{37}$ que encabeza la comedia El alcalde mayor (1604-1612) ${ }^{38}$, se pueden leer los siguientes latines:

...quien escucha tantas por escrito, quiero yo presumir que está distante, pero no ausente. Y tendré por infelicidad que V. m. juzgase por ingrato mi ánimo, faltando a esta correspondencia con menos causa. Bien sé que el agradecimiento es ley de la naturaleza, y fue sentencia de Plutarco que Civilia iura violari possunt, naturae non possunt ${ }^{39}$.

En este caso, el dramaturgo madrileño será más hormiga que abeja. La sentencia parece tener un origen claro: los Apophthegmas plutarqueos. En principio, siempre que lidiamos con las notas de erudición lopescas, lo más razonable sería pensar en una fuente indirecta, como la colección de apotegmas de Erasmo, extraídos en su mayoría de la obra homónima de Plutarco ${ }^{40}$. En sus pági-

34 Algunos años antes, concretamente en 1533, Diego Gracián había publicado una traducción de los Apotegmas, que proclamaba ser la primera "de lengua griega en castellana" (en T. Beardsley, Hispano-Classical translations printed between 1482 and 1699, Duquesne University Press, Pittsburgh, 1970, p. 34). Traducción que fue incluida en las Morales.

${ }^{35}$ En el mismo año y la misma ciudad -Amberes-se publica otra versión de los Apotegmas, por el maestro Juan de Jávara, que T. BEARDSLEY no recoge.

36 Por motivos obvios, hemos excluido las traducciones del siglo XVII posteriores a la muerte de Lope.

${ }^{37}$ Residente en México por aquel entonces, el doctor Núñez nació en Huete, ejerció como médico en Alcalá-donde es de suponer que conoció a Lope- y fue el autor de De coctione et pudredine (1613).

38 De aquí en adelante todas las fechas de composición están tomadas de la cronología de S. G. Morley y C. Bruerton, Cronología de las comedias de Lope de Vega, Gredos, Madrid, 1968.

${ }^{39}$ L. DE VEGA, "El alcalde mayor", en Trezena parte de las comedias de Lope de Vega Carpio, Viuda de Alonso Martín, Madrid, 1620, ff. 1r-v.

${ }^{40} \mathrm{Su}$ difusión universitaria y posterior éxito comercial, como atestiguan las numerosas reimpresiones a lo largo del siglo xvi, lo convirtieron en libro 
nas, cuenta el humanista holandés que Dionisio el Viejo (430-367 a.C.) fue interpelado por su anciana madre para que le buscara un nuevo marido, a lo que el tirano de Siracusa respondió con la siguiente chreia: "Civilia, inquit, O mater iura violari possunt,

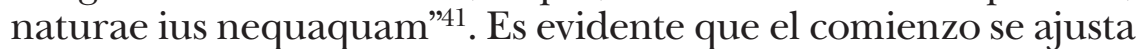
ad pedem litterae a nuestra sentencia, pero enseguida deriva hacia un final distinto. Habría, pues, que descartarla. No parece lógico, según creemos, que Lope copiara el principio de la frase y luego se dedicara a inventarse el resto. A nuestro juicio, ahora no se habría contentado con lucir una erudición de segunda mano, sino que habría recurrido a la fuente primaria, esto es, al propio Plutarco. Si acudimos a la traducción de Diego Gracián a las Morales, refiriéndose a Dionisio dice: "A su madre, que aunque era vieja quería marido dixo: Las leyes civiles se pueden traspasar, pero no las de natura" ${ }^{\prime 2}$. Aquella traducción tan literal, incluso pedestre, no deja asomo de duda. Más parece que Lope leyó el apotegma en español y luego lo trasladó a la lengua de Virgilio, que realmente lo tomara de un texto latino.

En otra de sus comedias, El dómine Lucas (1591-1595), brindada a su querido Juan de Piña, volvemos a toparnos con el escritor de Queronea en la dedicatoria; esta vez a cuenta del valor de la amistad:

En tres partes dividió Plutarco la amistad, que a mi parecer, ninguno con más claridad y acertamiento. Para amar los amigos, dijo que era necesario buen juicio; aquí entiendo el escogerlos, deleite en el conversarlos y seguridad de su ánimo en las necesidades que se ofreciesen. Todas tres partes he hallado en V. m. confirmadas en tantas ocasiones; que como este amor comenzó a los principios de la vida, tendrá a la misma fuerza hasta los últimos fines de su término ${ }^{43}$.

de cabecera para aquellos que deseaban barnizar su elocutio de sabiduría clásica.

${ }^{41}$ Erasmo, Apophthegmata, Johann Froben, Basilea, 1535, p. 429. En la traducción a cargo de Francisco Támara se puede leer: "O madre los derechos civiles bien se pueden quebrantar, mas el derecho de la naturaleza en ninguna manera se puede quebrantar" (Libro de Apothegmas, Martín Nucio, Amberes, 1549, ff. 244r-v).

42 D. Gracián de Alderete, Morales de Plutarcho traduzidos de lengua griega en castellana, Alejandro de Cánova, Salamanca, 1571, f. 4v.

43 L. DE VegA, "El dómine Lucas", en Obras completas. Comedias, III, eds. Jesús Gómez y Paloma Cuenca, Turner-Biblioteca Castro, Madrid, 1993, p. 644 . 
Sin dejar la traducción de Gracián a los Moralia, que Lope demuestra tener a mano, sólo necesitamos dirigirnos al breve tratado De la amistad derramada en muchos para descubrir nuestra referencia. Como portavoz de la tradición clásica, el polígrafo griego manifiesta un alto concepto de la amistad, a la que dedica más de un libro ${ }^{44}$, pero no será hasta aquel bello opúsculo cuando hallaremos una definición completa, canónica y sistematizada. Junto al epígrafe "La amistad requiere tres cosas", en la columna derecha del texto, leemos:

...la verdadera amistad principalmente requiere tres cosas, la virtud como cosa honesta, la conversación como cosa agradable y deleytosa, y el provecho y utilidad como cosa necessaria. Porque conviene escoger al amigo con juyzio, y conversarle con gozo y con alegría: y usar y aprovecharse dél quando fuere menester (Morales, f. 165r).

En esta ocasión, la cita no será tan literal, pero no deja lugar a la duda. De nuevo, Lope se vale de la traducción de Gracián para dar lustre a sus argumentos morales e impresionar al lector.

Otro ejemplo algo más escurridizo desenterramos en otra comedia: La francesilla (1596); concretamente en su dedicatoria, ahora ofrecida a un gran discípulo del Fénix, el doctor Juan Pérez de Montalbán: "Por eso Plutarco reprehende a los hombres, que procurando hacienda con tanta diligencia, no cuidan de que sean buenos los hijos a quien ha de dejarla" ${ }^{45}$. En esta ocasión, Lope se limita a glosar un apotegma que el polígrafo griego intercala en Sobre la educación de los hijos. La frase tan siquiera es original suya, pues está tomada del Clitofonte de Platón, aunque es razonable creer que fuera también de las Morales, a juzgar por este pasaje firmado por Diego Gracián:

No sin causa aquel [Só]crates antiguo dezía muchas vezes, que si pudiesse subirse en lo más alto de la ciudad, que daría vozes, diziendo. O hombres donde vays todos los que trabajays y procu-

${ }^{44}$ Para tener una visión panorámica del concepto de amistad en Plutarco, véase el artículo de A. Jiménez SAn Cristóbal a propósito del Quo pacto possis adulatorem ab amico dignoscere o De saber cómo podrá alguno determinar y diferenciar el amigo del lisonjero, según Gracián ("La noción de amistad en el De adulatore et amico", Cuadernos de Filología Clásica. Estudios Griegos e Indoeuropeos, 11, 2001, 255-277).

${ }^{45}$ L. DE Vega, "La francesilla”, en Obras completas. Comedias, IV, eds. J. Gómez y P. Cuenca, Turner-Biblioteca Castro, Madrid, 1993, p. 691. 
rays de allegar riquezas, y haziendas, y no teneys cuidado ninguno de los hijos aquien las aveys de dexar? (Morales, f. 126r).

Siguiendo los pasos de Plutarco en Lope, una dedicatoria más, ahora a El favor agradecido (1593), sirve para sacar a la luz otro fragmento de las Morales, aunque, a decir verdad, es posible que el dramaturgo madrileño se precipitara un tanto en dicha atribución:

...pues fue opinión de Plutarco: Que el alma veía y oía, y que todo lo demás era ciego y sordo. La mayor demostración de que ella ve y oye es el apacible semblante, de donde se colige que quien carece desta exterior dulzura, no mueve por el alma las acciones del beneficio $^{46}$.

Si leemos con detenimiento De la industria de los animales descubriremos lo siguiente: “...y dize el poeta: Vee y oye el entendimiento, / ciego, y sordo, es lo demás, / y será siempre jamás” (Morales, f. 265r). La correspondencia es diáfana e incluso se puede hablar de deuda. Cierto es que la frase es sucinta; no obstante, hay un dato que nos parece relevante. El hecho de que Lope atribuya estos versos al escritor de Queronea y no a Epicarmo de Siracusa, el verdadero autor de este epigrama, podría indicar que Lope se valió, en efecto, de aquel pasaje de las Morales, puesto que si hubiera sabido el nombre del "poeta", no se hubiera molestado en cambiar la autoría. No tendría sentido ocultar el dato. De hecho, en De la fortuna de Alejandro, otro librito incluido en las Morales, vuelven a aparecer los mismos versos, esta vez sí con nombre y apellidos: “...como dize Epicarmo, el entendimiento es el que vee, el entendimiento es el que oye, todo lo demás es ciego y sordo, y caresce de razón" (ibid., f. 60r). Por lo tanto, con las pruebas en la mesa, se podría apuntar, no sin prudente reserva, a una lectura de las Morales y en particular a De la industria de los animales.

En el acto primero de Lo cierto por lo dudoso (1612-1626), Lope vuelve a recurrir a Plutarco. La excusa será uno de los habituales chascarrillos en boca del gracioso. En esta ocasión, para poner paz en una pelea entre hermanos:

${ }^{46}$ L. DE Vega, "El favor agradecido", en Obras completas. Comedias, I, eds. J. Gómez y P. Cuenca, Turner-Biblioteca Castro, Madrid, 1993, pp. 245-246. 


$\begin{array}{ll}\text { RAMIRO } & \begin{array}{l}\text { Dijo un sabio reverendo, } \\ \text { que eran en anocheciendo } \\ \text { todas las mujeres unas. }\end{array} \\ \text { REY } & \begin{array}{l}\text { Habló del cuerpo, no dio } \\ \text { lugar al alma. }\end{array} \\ \text { D. ENRIQUE } & \begin{array}{l}\text { Epicuro } \\ \text { debió de ser. }\end{array} \\ \text { RAMIRO } & \begin{array}{l}\text { Pues yo os juro, } \\ \text { que Plutarco lo escribió }\end{array}\end{array}$

El proverbio está glosado, por lo que resulta más difícil identificar la fuente, pero tendría un origen clásico, concretamente griego. Lope no se equivoca y se lo atribuye con acierto a Plutarco, que en sus Preceptos y reglas del matrimonio escribió: "Una muger que por fuerça y contra su voluntad la llevavan al rey Philippo, dizen que dixo: Dexadme que toda muger apartada la candela es una misma" (Morales, f. 123r). De todas maneras, esta vez no podemos atribuirlo a una lectura de las Morales, no al menos de manera definitiva, pues la glosa en verso impide que podamos certificar el origen fidedigno de la cita. Sin ir más lejos, aquel aforismo fue recogido por Erasmo en su divulgadísima colección de adagios, bajo la forma "Sublata lucerna, nihil interest inter mulieres" (III.4.77), en la que sería la opción más plausible, dado que el humanista cita a Plutarco y sus Preceptos y reglas del matrimonio como la fuente del mismo.

Descubrimos un préstamo más nítido de las Morales en $\mathrm{El}$ principe perfecto, $2^{a}$ parte (1612-1618), leyendo la dedicatoria a don Alvaro Enríquez de Almansa, marqués de Alcañices: “...por quien dijo bien Plutarco que los Reyes eran ministros de Dios para el cuidado y salud de los hombres y para que los bienes que les dio, parte guardasen y parte distribuyesen" ${ }^{48}$. Como sucede en otros lugares, Lope no sólo estaría recordando el consejo plutarqueo, sino que lo estaría trasladando palabra por palabra. Si leemos el tratado De la doctrina del príncipe, en un momento determinado se dice: “...los príncipes son ministros de Dios para el cuydado y salud de los hombres: para que de los bienes que Dios les da a los hombres, dellos les repartan y dellos les guarden" (Morales, f. 116r). Poco más se puede añadir, excepto

${ }^{47}$ L. DE VegA, "Lo cierto por lo dudoso", en Obras escogidas. Teatro, I, ed. F. Sainz de Robles, Aguilar, México, 1991, p. 574.

${ }^{48}$ L. DE VEgA, "El príncipe perfecto. $2^{\mathrm{a}}$ parte", en Obras escogidas. Teatro, II, ed. F. Sainz de Robles, Aguilar, México, 1991, p. 1145. 
que Lope escribía según iba leyendo, de ahí las mínimas diferencias.

Otra comedia, El serafín humano (1610-1615), que narra diversos episodios de la vida de san Francisco de Asís, guarda una alusión a Plutarco en el primero de sus actos. En boca de un pobre se dice:

En la seguridad, Plutarco dice que el rico diferencia del que es pobre, y aunque esto, al ser verdad, no contradice, es bueno que lo diga a quien le sobre ${ }^{49}$.

De nuevo, a vueltas con la traducción de Gracián: “...ni quites a la pobreza aquella seguridad, y aquel estar sin cuidado, en que solamente parece que diffiere de las riquezas" (Morales, f. 188v). Estas líneas, sacadas del brevísimo Que no se debe tomar a logro, que podría considerarse como un complemento al Contra la codicia de las riquezas, vienen a reflexionar sobre el carácter imperturbable de la pobreza, que no teme a los cambios de fortuna como lo haría un rico, pues no tiene ya nada que perder.

Encontramos otro ejemplo en El villano en su rincón (1611), acto primero, donde topamos con una leyenda hecha historia sobre Semíramis y el magno mausoleo que mandó construir en Babilonia:

REY Plutarco hace mención, y por testigo pone a Herodoto, del sepulcro insigne que en la puerta mayor de Babilonia hizo la gran Semíramis de Nino, convidando a tomar de sus dineros al rey que dellos fuese codicioso. Abrióle Darío, rey de Persia, y dentro halló sola una piedra que decía: "Si no fueras avaro y ambicioso, no vieras las cenizas de los muertos" ${ }^{50}$.

Visto que este cuentecillo se convirtió pronto en un lugar común en misceláneas, polianteas y florilegios, la dificultad para rastrear la fuente sería máxima. Y es que, aunque esta his-

49 L. DE VEGA, "El serafín humano", en Obras de Lope de Vega, ed. M. Menéndez Pelayo, Atlas, Madrid, 1965, t. 11, p. 19.

${ }^{50}$ L. DE VEGA, El villano en su rincón, ed. J. M. Marín, Cátedra, Madrid, 1999 , p. 116. 
toria se recoge en las Morales, tal y como avisa Lope, existen ciertos detalles que no concuerdan con la narración del escritor de Queronea:

Semíramis haziendo ella misma su sepulcro escrivió en él. Qualquiera Rey que oviere menester dineros, derribe el sepulchro: y tome los que quisiere. Pues como Darío abriesse el sepulchro: ningunos dineros halló: sino otras letras que dezían. Si no fueras malo, y sedientos de dinero: nunca trastornarás los huesos, y ataúdes de los muertos (Morales, f. 2r).

Como acabamos de señalar, los relatos de uno y otro son aparentemente disconformes: el monumento funerario es en honor de Semíramis y no para enterrar a su marido, el rey Nino ${ }^{51}$. En un primer momento se podría pensar que esta divergencia se debería a un error o glosa de Gracián, pero la magna traducción de Erasmo a los apotegmas plutarqueos tampoco aporta nada diferente. Ni siquiera podemos dirigir la mirada hacia Herodoto, a quien el Fénix sitúa como el primero en dar la noticia, pues ambas versiones son idénticas, salvo en el nombre de su protagonista, pues para el protohistoriador la inventora de aquel artificio fue Nitocris, otra reina asiria (Herod. I, 187). Por lo tanto, sin ser categóricos, lo más plausible es que fuera otra lectura de las Morales.

Finalmente, como dato curioso, exponemos la única cita plutarquea usada por Lope que no pertenecía a una obra traducida en las Morales. De hecho, no conocería ninguna versión castellana en vida de Lope. Nos estamos refiriendo a las Quaestiones convivales, que tienen su cuota de protagonismo en Servir a señor discreto (1610-1615), otra comedia:

GIRÓN

$$
\begin{aligned}
& \text { Allá en Plutarco he leído } \\
& \text { que aunque de suyo el amor } \\
& \text { es en extremo hablador } \\
& \text { nunca con tanto lo ha sido } \\
& \text { como queriendo alabar } \\
& \text { lo que ama }{ }^{52} \text {. }
\end{aligned}
$$

51 Otra posibilidad sería una lectura alternativa con "hizo la gran Semiramís de Nino" como una simple referencia a que Semíramis era consorte de Nino, rey de los asirios.

${ }^{52}$ L. DE VeGA, Servir a señor discreto, ed. F. Weber de Kurlat, Castalia, Madrid, 1975, p. 139. 
Este fragmento, que ni su editora, Weber de Kurlat, ni Maria Grazia Profeti consiguieron identificar ${ }^{53}$, se puede leer en sus Quaestiones: “...y realmente, con ser mucho el placer con que miran a sus amados, los encomian con no menos gusto que los miran, y es que el amor, siempre locuaz, lo es mucho más en los elogios" $"$, en lo que vendría a ser un préstamo directo de Plutarco y, por consiguiente, un indicio para creer que Lope no sólo se valía de las Morales para leer al polígrafo griego.

\section{VIDAS PARALELAS}

Ya hemos señalado que en el Siglo de Oro la fortuna de las Vidas paralelas corrió junto a la de los Moralia, aunque en el Renacimiento se advierta un cambio de tendencia respecto a épocas medievales, cuando la importancia del Plutarco historiador prevalecía sobre el moralista. Así, como atestigua el catálogo de T. Beardsley, sólo se llevaron a la imprenta un reducido número de traducciones: una incompleta con el título, Las vidas de los ilustres y excelentes varones griegos y romanos, por el doctor Francisco de Enzinas (1551), profesor de griego en Cambridge ${ }^{55}$, la brevísima Heroicos hechos y vidas de varones ilustres, de fray Tomás de Espinosa (1576), y la anónima Vidas de Cimón griego y Lucio Lucullo romano (1547), aunque atribuida tradicionalmente a Enzinas. Sin olvidar una Vida de Cicerón a cargo de Juan Lorenzo Palmireno a partir de una versión latina. En definitiva, un panorama editorial escuálido si lo comparamos con algunos países del entorno ${ }^{56}$.

Como veremos a continuación, en nuestro corpus no existe una sola referencia plutarquea que pertenezca a alguna de las Vidas ya traducidas en tiempos de Lope, por lo que se hace obli-

53 M. G. Profeti, "Plauto, Lope y el teatro áureo”, AnLV, 12 (2006), p. 209.

54 Plutarco, Obras morales y de costumbres (Moralia). T. 4: Charlas de sobremesa, ed. F. Martín García, Gredos, Madrid, 1987, p. 80.

${ }^{55}$ La traducción, que se anuncia como una primera parte, contiene las vidas de Teseo, Rómulo, Licurgo, Numa, Solón y Publícola. Al final del volumen se incluyen dos más -Temístocles y Camilo- de atribución dudosa, aunque parecen ser de Enzinas.

56 En Francia, las Vidas paralelas traducidas por Jacques Amyot (1559) conocen hasta diez ediciones antes de terminar el siglo y las reediciones latinas son aún más numerosas. Y las pocas traducciones castellanas ni siquiera eran españolas: la de fray Tomás de Espinosa se publicaba en París y la del doctor Enzinas en Estrasburgo. 
gado el pensar que Lope, ahora sí, recurrió a versiones latinas, ya fueran completas o resumidas en alguna poliantea.

En una primera comedia, La doncella Teodor (1610-1612), la protagonista pronuncia ante el Soldán de Persia un largo encomio a diferentes mujeres ilustres de la Antigüedad, entre las que menciona a Targelia con un lacónico "Plutarco alaba a Targelia" ${ }^{57}$. La cita sería correcta. En efecto, si acudimos a la Vida de Pericles se compara a Aspasia con una hetaira aún más famosa que ella:

Dicen que siguiendo el ejemplo de Targelia, una antigua cortesana de Jonia, sedujo a los hombres más poderosos. Pues también Targelia, mujer de belleza extraordinaria que unía el encanto a la sagacidad, cohabitó con un gran número de griegos y a todos los que tuvieron relaciones sexuales con ella se los atrajo a la causa del rey de Persia, y mediante aquellos hombres, que eran los más poderosos e influyentes, fue sembrando insensiblemente en las ciudades los primeros gérmenes del medismo ${ }^{58}$.

Ahora bien, a este particular habría que advertir que la fuente no estaría en Plutarco, no al menos de forma directa, sino en Ravisio Téxtor, pues, como ya probamos en un trabajo anterior ${ }^{59}$, aquella lista de damas doctas fue compuesta con la Officina en una mano y la pluma en la otra.

En otro lugar, concretamente en el primer acto de El hombre por su palabra (1612-1615), nos topamos con una doble alusión plutarquea, ya que, por un lado, tenemos la historia de Parisatis y su esclava Giges, y, por otro, el sanguinario castigo que los antiguos persas reservaban para los envenenadores:

[AlejANDRo] La madre del Gran Ciro se valía de Giges, famosísima hechicera, y Persia entre dos piedras las molía, que les daba por ley muerte tan fiera. Plutarco la refiere ${ }^{60}$.

${ }^{57}$ L. DE Vega, La doncella Teodor, ed. J. González-Barrera, Reichenberger, Kassel, 2008, p. 359.

58 Plutarco, Vidas paralelas: Alejandro-César, Pericles-Fabio Máximo, Alcibiades-Coriolano, ed. E. Crespo, Cátedra, Madrid, 1999, p. 292.

${ }^{59}$ J. GonzÁlez-Barrera, "Lope de Vega y los «librotes de lugares comunes»: su lectura particular de Ravisio Téxtor", AnLV, 13 (2007), pp. 51-71.

${ }^{60}$ L. DE VEGA, "El hombre por su palabra", en Obras de Lope de Vega, Real Academia Española-Tipografía de Archivos, Madrid, 1928, t. 6, p. 359. 
La referencia la hallamos en la Vida de Artajerjes, donde el escritor de Queronea narra el asesinato de Estatira, esposa del Gran Rey, por un envenenamiento orquestado por la madre de éste, Parisatis, que andaba celosa de su creciente influencia sobre Artajerjes:

Así pues Parisatis se mantuvo firme desde el principio en su odio contra Estatira y sus celos y, al comprobar que su propia influencia se basaba en el respeto y la estima del rey, pero que el amor y la intimidad de la otra era una influencia más fuerte y poderosa, se atrevió a urdir una conspiración, arriesgándole todo por el todo, tal como se cree.

Parisatis tenía una criada leal e influyente a su servicio, con el nombre de Gigis, que Dinón dice que participó en el envenenamiento... Según la ley los envenenadores mueren en Persia de esta manera: tras poner sobre una piedra plana la cabeza, los golpean y aprietan con otra piedra hasta que les trituran la cabeza y el rostro. Gigis murió asíí ${ }^{61}$.

En este caso, sobre todo en lo concerniente a las leyes persas, no se puede descartar que la fuente fuera un centón de los muchos que hubieran podido recoger la noticia; por ejemplo, tanto en la divulgadísima Officina de Ravisio Téxtor ${ }^{62}$ como el Dictionarium historicum, geographicum, poeticum de Carolus Stephanus, bajo la voz Gyge se lee: “.... ancilla fuit Parysatis regihae Persarum \& matris Cyri. Plut" 63 . Si bien no se puede negar que la fuente principal de la noticia es el polígrafo griego y su Vida de Artajerjes.

Según la dedicatoria a El verdadero amante (1588-1595), dirigida a su hijo Lope, fruto de su relación con Micaela de Luján, sólo dos autores clásicos habían logrado definir lo que era un genio: "Vos quedasteis en su lugar, no sé con cuál genio, cuya definición os dirán Pausanias y Plutarco, cuando sepáis entenderlos;

61 Plutarco, Vidas paralelas. VII: Demetrio-Antonio, Dión-Bruto, AratoArtajerjes-Galba-Otón, eds. J. P. Sánchez Hernández y M. González González, Gredos, Madrid, 2009, pp. 532-533.

${ }^{62} \mathrm{~J}$. Ravisius TeXTOR, Officina nunc demum post tot editiones diligenter emendata, aucta $\mathcal{E}^{\circ}$ in longè commodiorem ordine redacta per Conradum Lycosthenem Rubeaquensem, Herederos de Bryling, Basilea, 1566, p. 412.

63 “...fue criada de Parisatis, reina de los persas y madre de Ciro. Plutarco” (C. Stephanus, Dictionarium historicum, geographicum, poeticum, Jacob Stoer, Frankfurt, 1590, f. 123v, la traducción es mía). 
el uno en los Acaicos, y el otro en la Vida de Bruto"64. Las dos referencias son correctas. Pausanias había dicho en el libro dedicado a la Acaya de su Descripción de Grecia que Genio -también llamado Agditis- era el hijo de Zeus y la Tierra (VII, 17, 10-12). Y Plutarco le puso voz a uno en su Vida de Bruto. Para los antiguos, los genios eran daimones que intentaban persuadirnos en una u otra dirección, imprimiendo imágenes o haciendo aparecer fantasmas como en un espejo. Eran capaces de mirar en el interior de los hombres, por lo que conocían los miedos, deseos y preocupaciones que desgobiernan nuestro espíritu. Semejantes a los ángeles de la guarda en la teología cristiana. En la Vida de Bruto un genio se aparece al romano poco antes de la decisiva batalla de Filipos:

Él, envuelto en sus razonamientos y reflexiones, creyó sentir que alguien se acercaba. Girando la vista a la entrada, ve una imagen terrible y singular, de un cuerpo extraño y temible, colocado en silencio a su lado. Tomando ánimo, dijo: “QQuién, hombre o dios, eres?, ¿qué quieres de mí?”. El fantasma respondió con voz baja: "Bruto, soy tu mal daimon; volverás a verme en Filipos". Y Bruto dijo, sin turbarse: "Te veré" (Vidas paralelas, VII..., p. 373).

Como detalle interesante, no podemos dejar de comentar el desenlace de nuestra historia. Conmocionado por aquel encuentro, Bruto corre a contárselo a su amigo Casio, que intenta disuadirlo de que los fantasmas no existen:

En tu caso, tu cuerpo fatigado, naturalmente, tiene en suspenso el juicio y lo lleva de un lado a otro. No es verosímil que existan fantasmas ni que, si existieran, tuvieran figura humana, o voz, o la capacidad de acercarse a nosotros (ibid., p. 374).

Argumentos, por cierto, que a pesar de su semblanza moderna, tienen una fuerte carga epicúrea ${ }^{65}$.

Por último, a modo de cierre, en el primer acto de la comedia Servir a señor discreto, a la que ya nos referimos anteriormen-

${ }^{64}$ L. DE VEGA, "E1 verdadero amante", en Obras completas. Comedias, II, eds. J. Gómez y P. Cuenca, Turner-Biblioteca Castro, Madrid, 1993, p. 85.

65 F. BRENK, “Cassius' «Epicurean» explanation of Brutus' visions in Plutarch's Brutus", en Relighting the souls: Studies in Plutarch, in greek literature, religion, and philosophy, and in the New Testament background, Frank Steiner Verlag, Stuttgart, 1998, p. 119. 
te, Lope enmascara una segunda referencia al polígrafo griego, ahora a cuenta de sus Vidas paralelas:

[Elvira] Señor una vez contó que antes que saliese a hablar en público un orador de Grecia, en frente colgaba un espejo en que miraba qué efeto sería mejor ${ }^{66}$.

Como ya anotara Weber de Kurlat en su edición filológica, esta anécdota está recogida en la Vida de Demóstenes, donde se cuenta que aquel "orador de Grecia" practicaba su elocuencia frente a un espejo: “...tenía en casa un grande espejo y que, puesto enfrente, recitaba, viéndose en él, sus discursos" ${ }^{67}$. De todas maneras, el relato es demasiado conocido como para descartar otra posible fuente, considerando la gran cantidad de repertorios a la mano en tiempos de Lope. De hecho, incluso Sebastián de Covarrubias se acuerda del famoso orador griego en su larga descripción de la voz espejo: "Algunos han usado dél para componer y moderar sus acciones y movimientos del cuerpo y rostro, como escriben lo hacía Demóstenes cuando había de hablar en público"68.

\section{Conclusiones}

En suma, a veces abeja, a veces hormiga, pero siempre gusano de seda, no queda atisbo de duda de que Lope utilizó las Morales de Diego Gracián de Alderete para trufar de erudición plutarquea sus cartas, dedicatorias y comedias. Sin entrar en el estéril debate sobre si sabía mucho o poco latín, integrando la crítica filológica tradicional bajo el prisma de la cultura material, creemos probado que no se molestaba en traducir los pasajes, sino que leía y copiaba directamente de la versión española, que debió poseer, dada la rotundidad de las pruebas. Como advertimos al principio, no se trata de agotar el tema, pues estamos conven-

66 L. DE VEGA, Servir a señor discreto, pp. 107-108.

67 Plutarco, Vidas paralelas: Demóstenes-Cicerón, Demetrio-Antonio, trad. A. Ranz Romanillos, Espasa-Calpe, Buenos Aires, 1948, p. 16.

${ }^{68}$ S. De Covarrubias Orozco, Tesoro de la lengua castellana o española, ed. F.C.R. Maldonado, Castalia, Madrid, 1995, p. 507. 
cidos de que otras referencias al de Queronea están enterradas bajo los versos de su teatro. En lo concerniente a los Moralia, las que aquí hemos presentado son citas o alusiones que parecen tener una única fuente, porque llama poderosamente la atención que todas ellas, salvo una, tengan como origen libritos o tratados traducidos por Gracián, lo que evidenciaría un claro manejo en castellano. Por ende, a la biblioteca de Lope de Vega, de la que no se conserva ningún inventario, pero que desde siempre ha atraído la atención, interés y curiosidad de los especialistas, incluyendo o quitando volúmenes, se le podría añadir las Morales en una de las estanterías junto a su mesa de estudio.

JULián GONZÁlEZ-BARRERA Università Ca'Foscari di Venezia 